\title{
Impact of routine sanitation on the microbiomes in a fresh produce processing facility
}

\author{
Ganyu Gu ${ }^{\mathrm{a}, \mathrm{b}}$, Andrea Ottesen ${ }^{\mathrm{c}}$, Samantha Bolten ${ }^{\mathrm{a}}$, Lan Wang ${ }^{\mathrm{d}}$, Yaguang Luo ${ }^{\mathrm{a}}$, Steve Rideout ${ }^{\mathrm{b}}$, \\ Shuxia Lyu ${ }^{\mathrm{d}}$, Xiangwu Nou ${ }^{\mathrm{a}, *}$
}

${ }^{a}$ Environmental Microbiology and Food Safety Laboratory, USDA ARS, Beltsville, MD, United States

${ }^{\mathrm{b}}$ Eastern Shore Agricultural Research and Extension Center, Virginia Tech, Painter, VA 23420, United States

${ }^{c}$ Center for Food Safety and Applied Nutrition, US Food and Drug Administration, College Park, MD 20740, United States

${ }^{\mathrm{d}}$ Shenyang Agricultural University, College of Biological Science and Technology, Shenyang, China

\section{A R T I C L E I N F O}

\section{Keywords:}

Fresh-cut processor

Zone 3 surface, 16S rRNA gene copy number

Residential microbiota

\begin{abstract}
A B S T R A C T
Indigenous bacterial populations in fresh-cut produce processing facilities can have a profound effect on the survival and proliferation of inadvertently contaminating foodborne pathogens. In this study, environmental samples were collected from a variety of Zone 3 sites in a processing plant before and after daily routine sanitation. Viable mesophilic aerobic bacteria population was evaluated using both culturing method and quantitative real-time PCR (qPCR) after propidium monoazide treatment. Zone 3 surface microbiota were analyzed using 16S rRNA gene amplicon sequencing with the Qiime2 bioinformatic pipeline. Over 8000 bacterial species across 4 major phyla were identified in Zone 3 microbiomes in the processing facility. Overall, effective bacterial reduction was observed at the sampling sites on the production floor, while sanitation effect on peripheral surfaces was less evident. Effective sanitation resulted in both quantitative and qualitive shifts of Zone 3 microbiota. Several species were highly abundant at multiple sample sites for both winter and summer samplings. Based on the spatial and temporal distribution of the most abundant species, a Zone 3 core microbiome in the processing facility was tentatively described to included Cupriavidus sp., Pseudomonas sp., Ralstonia sp., Arthrobacter psychrolactophilus, Pseudomonas veronii, Stenotrophomonas sp., and an unknown species of the family Enterobacteriaceae.
\end{abstract}

\section{Introduction}

Contamination of fresh produce by foodborne pathogens could be originated at various stages of production, including field growth and post-harvest processing. Recent examples are Escherichia coli 0157 contamination on ready-to-eat salad in 2013, and on alfalfa sprouts in 2016; Listeria monocytogenes contamination on cantaloupe in 2011, and on packaged salads in 2016; and Salmonella contamination on tomatoes in 2006, and on pre-cut melon in 2018 (CDC, 2018). An environment that is arguably more important for food safety risk assessment but to date has received less attention, is the processing environment. Even though environmental bacteria are generally not considered food safety concerns, they are important indicators of the environmental hygiene of the processing facility (Ferreira et al., 2014; Moretro and Langsrud, 2017; Pérez-Rodríguez et al., 2018). Thus, cleaning and sanitizing are usually performed at the end of production shift to remove plant debris, soils, and microbial contaminants that accumulate on surfaces during processing (Moretro and Langsrud, 2017) and is a part of an overall food safety program for most food processing plants. Proper sanitation is also a requisite of Good Manufacturing Practices (GMPs) that food processors must comply. However, bacteria have varying degrees of tolerance to routine sanitation, and some may colonize and persist in the environment by forming biofilms. These residential bacteria may be transmitted to food products and potentially affect food quality and safety (Moretro and Langsrud, 2017).

Investigating the effect of sanitation and environmental conditions on microbial communities in food processing environments can provide exciting possibilities for understanding microbial dynamics of food ecosystems and ultimately lead to safer, more efficient, and sustainable food-production practices (Bokulich et al., 2016). The total bacterial counts, such as APC (aerobic plate count), have been commonly used by industry to evaluate the efficiency of sanitation processes. However, the identity of the bacteria in produce processing environments and their impact on food quality and safety are mostly unknown (Moretro and

\footnotetext{
* Corresponding author.

E-mail address: xiangwu.nou@ars.usda.gov (X. Nou).
} 
Langsrud, 2017). Bacterial contamination within fresh produce processing factories has been addressed in several studies using traditional microbiological methods based on cultivation and molecular typing (Aguado et al., 2004; Holah et al., 2004; Kaneko et al., 1999; Pappelbaum et al., 2008). Nevertheless, compared to studies of the microbiota in other food production environments, such as seafood processing (Moretro et al., 2016), meat, and dairy processing (Hultman et al., 2015; Stellato et al., 2017) environments, microbiota associated within fresh produce processing facilities have not been extensively analyzed with metagenomics approaches. Additionally, little is known about the effect of routine sanitation practices in fresh-cut produce processing facilities on the diverse microbial communities on various types of environmental surfaces (Moretro and Langsrud, 2017).

Food manufacturers typically manage facilities by zoning (Brouillette, 2018; FDA, 2018; Simmons and Wiedmann, 2018). Zone 1 is composed of surfaces that are in direct contact with food materials, such as flumes and conveyer belts, and Zone 2 typically include equipment used for food processing excluding surfaces that directly contact the unpackaged foods. Zone 3 refers to surface areas in the processing facility excluding Zones 1 and 2, such as floors, drainage, walls etc., while Zone 4 refers to external surfaces associated with food processing, such as hallways, break rooms etc. Zone 3, while not in direct contact with food materials, are diverse niches and can harbor microbial communities that potentially interact with Zones 1 and 2, and the safety outcomes of the food products. In this study, the Zone 3 microbiome was assessed in the fresh-cut produce processing environment impacted by sanitation. The DNA-modifying dye propidium monoazide (PMA) was applied during sample preparation to ensure the focus on viable microbial communities on surface samples (Chiao et al., 2014; Nocker et al., 2010). Quantitative-PCR (qPCR) estimation of $16 \mathrm{~S}$ rRNA gene copies was incorporated with sequencing data to analyze the absolute abundances of specific bacterial taxa across different samples (Gu et al., 2018).

\section{Materials and methods}

\subsection{Food environmental surface sample collection and processing}

In this study, a large commercial fresh-cut produce processing plant in eastern United States was sampled twice in late winter (end of February) and early summer (mid-June) of 2017. At each sampling time, environment surface samples were collected at 10 Zone 3 nonfood contact surface areas at the end of production shift before daily sanitation, and after sanitation but before the start of the morning shift. The temperature of the processing facility was maintained at about $5{ }^{\circ} \mathrm{C}$.

The 10 Zone- 3 sites covered areas at the production floor, including two cement floor locations (CF1 and CF2), two mezzanine floor locations (MF1 and MF2), and two drain covers (DC1 and DC2), and at the peripheral surfaces, including two entrance doors (DR1 and DR2) and two walls (WL1 and WL2). The materials of sampled surfaces include acrylic-modified cement (Floor and Wall), metal (Mezzanine floor and Drain cover), plastic and metal (Door: polyvinyl chloride door panel and metal handle). Sites CF1, CF2, and MF1 were alongside one processing line, proximal to the start (spinach loading) and the end (dewater centrifuge) of the washing operation, and the start (platform for the weigh-distributer) of the packing operation, respectively. Site MF2 is another mezzanine floor adjacent to a different flume. Sites DC1 and DC2 were drain covers on the washing floor. Sites DR1 and DR2 were the in-side of two entrance doors that are primarily used by workers and technical staff, and samples were taken targeting the handle and the surrounding area. Sites WL1 and WL2 were front and rear sides of the walls, and samples were taken at areas about $1.5 \mathrm{~m}$ above the floor.

An area of $400 \mathrm{~cm}^{2}$ of the selected surface at each sampling site was defined with a sterile template and sampled by vigorously rubbing ten times with a sterile sponge (Whirl-Pak, Nasco, Fort Atkinson, WI) hydrated with $20 \mathrm{ml}$ of sterile Dey/Engley Neutralizing Broth (D/E;
Becton, Dickinson and Company, Franklin Lakes, NJ). For surfaces with uneven contours, the sampled areas were approximated. Samples of the same sites before and after sanitation were collected from adjacent areas of surface. Sampling sponges were placed in sterile stomacher bags (Whirl-Pak) and transported to the laboratory on ice. All samples were processed within $5 \mathrm{~h}$.

Sample sponges were pummeled for $2 \mathrm{~min}$ in a stomacher (Lab Blender, Seward Medical, Ltd., Sussex, UK) and the liquid squeezed out by hand. The same process was repeated by transferring the liquid into a tube and replenishing the bag with another $20 \mathrm{ml} \mathrm{D} / \mathrm{E}$ broth to enhance microbial recovery from the sponge. Combined liquid $(40 \mathrm{ml})$ of each sample was filtered by a sterile Whirl-Pak filter bag (Nasco, Fort Atkinson, WI) with $0.3 \mathrm{~mm}$ perforation, and split into four $10-\mathrm{ml}$ portions. In total, 160 surface samples were processed for following plate count, qPCR and sequencing analyses.

\subsection{Bacterial enumeration}

For plate counting, $100 \mu \mathrm{l}$ of the filtrate of each sample and its 10fold dilution were spiral plated on tryptic soy agar plates with polysorbate and lecithin (TSA-PL, Sigma, St. Louis, MO), and vegitone plate count agar plates (PCA-V, Sigma) in duplicates as described previously (Gu et al., 2018). Plates were incubated at $30^{\circ} \mathrm{C}$ for 2 days and all colonies enumerated using a Flash \& Go automatic colony counter (IUL, Barcelona, Spain). Total bacterial population was also estimated by qPCR, as described below.

\subsection{PMA treatment and DNA extraction}

The split filtrate $(10 \mathrm{ml})$ was centrifuged for $15 \mathrm{~min}$ at $4500 \mathrm{~g}$ to precipitate bacterial cells. The precipitated cells were further concentrated by microcentrifugation $(14,000 \mathrm{~g}$ for $10 \mathrm{~min})$. Finally, pelleted cells were re-suspended in $500 \mu \mathrm{l}$ PBS with $50 \mu \mathrm{M}$ DNA-modifying dye propidium monoazide (PMA, Biotium, Fremont, CA). The cell suspension was incubated in dark for $10 \mathrm{~min}$ at room temperature, followed by light exposure for $10 \mathrm{~min}$ at a distance of $20 \mathrm{~cm}$ from a $650-\mathrm{W}$ halogen light source (Sachtler R651HS; Camera Dynamics, Inc., Valley Cottage, NY) on ice as described by Chiao et al. (2014). Cells were washed with PBS twice and collected by centrifugation at $14,000 \mathrm{~g}$ for $10 \mathrm{~min}$.

PMA treated cells were re-suspended in $150 \mu \mathrm{TE}$ buffer (Thermo Fisher Scientific) with $10 \mathrm{mg} / \mathrm{ml}$ lysozyme (Epicentre, Madison, WI) and $5 \mathrm{mg} / \mathrm{ml}$ proteinase $\mathrm{K}$ (Eicentre), and incubated at $37^{\circ} \mathrm{C}$ for $10 \mathrm{~min}$. Bacterial DNA of each sample was extracted using Mobio Powersoil DNA isolation kit (Qiagen, Gaithersburg, MD) following the supplier's instructions. Extracted genomic DNA was stored at $-80^{\circ} \mathrm{C}$ until use.

\subsection{Quantitative real-time PCR ( $q P C R$ )}

qPCR targeting a highly conserved $180 \mathrm{bp}$ portion of $16 \mathrm{~S}$ rRNA gene (Clifford et al., 2012) was performed on a Mx3005P QPCR system (Agilent technology Inc. Savage, MD) to estimate the total 16S rRNA gene copy numbers. Each $25 \mu \mathrm{l}$ reaction mix contained $12.5 \mu \mathrm{l}$ of $2 \times$ QuantiTect GotoTaq qPCR Master Mix (Promega, Madison, WI), $1 \mu \mathrm{l}$ of forward and reverse primers to a final concentration of $0.5 \mu \mathrm{M}, 8.5 \mu \mathrm{l}$ water, and $2 \mu \mathrm{l}$ DNA templates with proper dilution if necessary. Standard curves were generated in every qPCR run using serial dilutions of chromosomal DNA of known concentration extracted from $E$. coli using the same method. In brief, the 16S rRNA gene copy numbers of $E$. coli DNA standards were defined as reported before (Brankatschk et al., 2012). The total 16S rRNA gene copy numbers were calculated based on the linear regression of the logarithm values of standards and cycle threshold $\left(\mathrm{C}_{\mathrm{T}}\right)$ values of $\mathrm{qPCR}$. $\mathrm{C}_{\mathrm{T}}$ numbers and baseline were determined automatically using the Noiseband algorithm. All PCR were performed in triplicate. The inferred absolute abundances of identified taxa in the surface DNA samples were calculated by multiplying the 

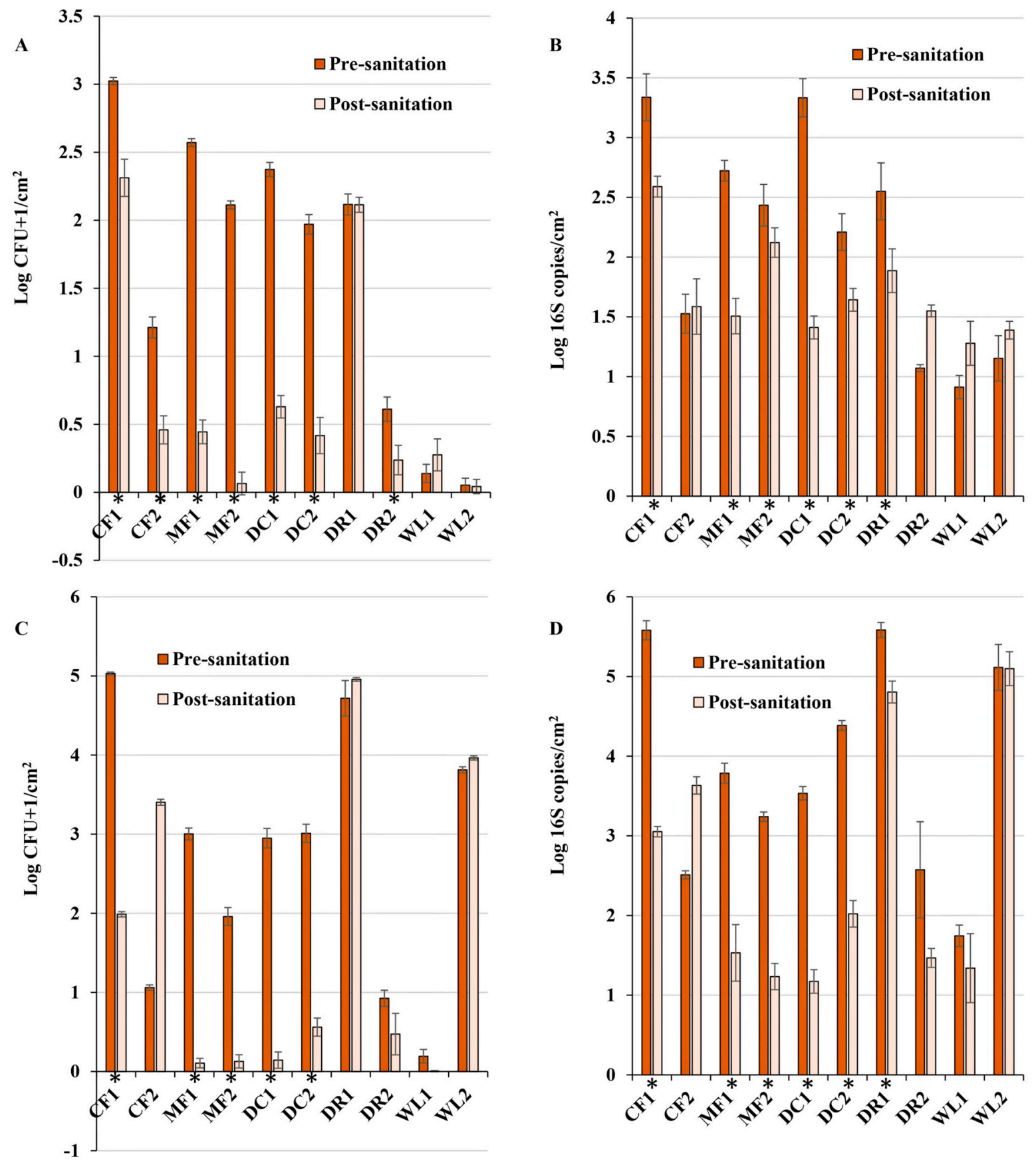

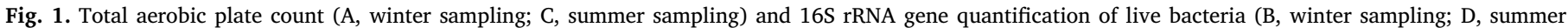
sampling) on environmental surfaces subjected to routine sanitization.

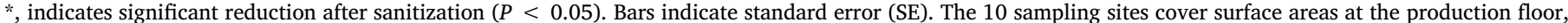

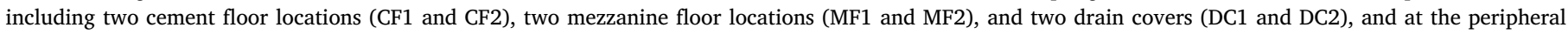
surfaces, including two entrance doors (DR1 and DR2) and two walls (WL1 and WL2).

total 16S rRNA gene copy numbers of each sample by the taxonomic relative abundance (RA) of each taxon in the sample calculated from the 16 S amplicon sequencing described below (Liang et al., 2015).

\subsection{S rRNA gene amplicon sequencing and sequence analysis}

Sample DNAs were processed for $16 \mathrm{~S}$ amplicon sequencing following the Earth Microbiome Project protocol (Caporaso et al., 2012; Caporaso et al., 2011) using MiSeq (Illumina). MiSeq Reagent 600-cycles v3 and 500-cycles v2 kits (Illumina) were used for sequencing winter and summer samples, respectively. The barcode primer sets of
515F and 806R were used to amplify the 16S rRNA gene fragment (Apprill et al., 2015; Parada et al., 2016). The v4 region of bacterial 16S rRNA gene was targeted for metagenomic analyses.

Illumina sequence data were sorted based on unique barcodes and quality-controlled using the Quantitative Insights Into Microbial Ecology Qiime2 (version 2017.8, https://docs.qiime2.org/2017.8/) with plugins demux (https://github.com/qiime2/q2-demux), dada2 (Callahan et al., 2016) and feature-table (McDonald et al., 2012). Alpha and beta diversity analyses were performed by using plugins alignment (Katoh and Standley, 2013), phylogeny (Price et al., 2010), diversity (https://github.com/qiime2/q2-diversity), and emperor (Vazquez- 
Baeza et al., 2013). A pre-trained Naive Bayes classifier based on the Greengenes 13_8 99\% OTUs database (http://greengenes. secondgenome.com/), which has been trimmed to include the v4 region of $16 \mathrm{~S}$ rRNA gene, bound by the $515 \mathrm{~F} / 806 \mathrm{R}$ primer pair, was applied to paired-end sequence reads to generate taxonomy tables. Taxonomic and compositional analyses were conducted by using plugins feature-classifier (https://github.com/qiime2/q2-featureclassifier), taxa (https://github.com/qiime2/q2-taxa) and composition (Mandal et al., 2015).

\subsection{Statistical analysis}

With plate count enumeration and qPCR estimation, bacterial CFU values and 16S rRNA gene copy numbers were log transformed to present the population densities for normalization. Since the logarithm of zero is undefined, the plate count data and 16S copy numbers of the top five bacterial species were transformed using the formula $\log _{10}(\mathrm{CFU}+1)$ or $\log _{10}(16$ copies +1 ) (Kloepper and Beauchamp, 1992; Luo et al., 2016). Analysis of variance (ANOVA) was performed to analyze the difference of both bacterial populations by plate count and 16S rRNA gene copy numbers by qPCR among different type of samples. Pearson's correlation coefficients were calculated to evaluate the correlations between the shift in bacterial populations and $16 \mathrm{~S}$ rRNA gene copy numbers among samples collected from different sites before and after sanitization. The levels of top five bacteria species among different types of surface samples in the produce processing environments were also analyzed by ANOVA. To evaluate the impact of routine sanitization, sample sites/surface materials, and sampling times, the differences of alpha diversity indexes, including evenness and Shannon index, and beta diversity analysis by the Weighted UniFrac method, among samples were analyzed by Kruskal-Wallis $\mathrm{H}$ test and Permutational multivariate analysis of variance (PERMANOVA) analysis, respectively, in Qiime 2. All other statistical analyses were performed using SAS (SAS release 9.3, SAS Institute Inc., Cary, North Carolina). Except when stated otherwise, $P$ values of $<0.05$ were considered statistically significant.

\section{Results and discussion}

\subsection{Zone 3 microbial distribution and effectiveness of sanitation}

Identical Zone 3 surface areas in a fresh produce processing facility were sampled twice about 4 months apart for microbiome assessment. For each sampling, adjacent surface of identical dimensions was sampled before and after daily sanitation. Aerobic bacterial populations at these sampled sites were determined by non-selective plating on TSAPL and PCA-V (Fig. 1A and C). There was no significant difference between the cell counts on these plates (Data not shown), and hence data presented here was based on the calculation using the average cell counts on the two media.

Prior to sanitation, surface areas on the production floor (Sites CF1, CF2, MF1, MF2, DC1, and DC2) generally had relatively high counts of aerobic bacteria. An exception was Site CF2, which was adjacent to the de-watering centrifuge and was often inundated in produce wash water. On the other hand, the peripheral surfaces (Sites DR1, DR2, WL1, and WL2) had much lower aerobic bacterial counts, with exception for Site DR1, which is an entrance door of general use that leads to the dressing area. In the summer sampling, Site WL2, a wall surface to the back of the production floor, also exhibited exceptional high bacterial counts. After sanitation, all sites in the production area consistently showed significant reduction in aerobic bacterial population, except for Site $\mathrm{CF} 2$ during the summer sampling. This deviation was likely due to the fact that the sampled site was found inundated in produce wash water prior to the scheduled pre-sanitation sampling. Overall, the data is consistent with effective sanitation on the production floor. In contrast, for the peripheral surfaces (walls and doors) the reduction in aerobic bacterial population was often minimal, which suggested that sanitization on such surfaces was less effective. The low effectiveness at certain sampling sites could be due to multiple factors, including surface materials, surface construction, and sanitation quality, which were out of the scope of this study. While it was generally true (with exceptions as noted above) that sampled surface on the production floor had higher pre-sanitation contamination and higher microbial reduction by sanitation compared to the peripheral surface for both winter and summer samplings, those from the summer sampling overall yield significantly higher populations of aerobic microbial counts.

Total bacterial population at the sampled sites was also estimated by qPCR targeting16S rRNA gene (Fig. 1B and D). Similar to that observed by plate count, qPCR showed that16S rRNA gene copy numbers were, in general, significantly higher at sites on the production floor than those at peripheral surface, and that more significant reduction in $16 \mathrm{~S}$ rRNA gene copies was achieved at the sites on production floor. The estimated bacterial 16S rRNA gene copy numbers of these samples by qPCR were significantly correlated to the population density determined by plate count $(P<0.01)$. The significant increases of total $16 \mathrm{~S}$ rRNA gene copies on surface samples in summer sampling compared to winter sampling was also consistent with that observed by the plate counting as mentioned above. Overall, 16S rRNA gene copies calculated by qPCR were about 0.9 log higher than the aerobic bacterial populations determined by plate count. This was consistent with the multi-copy nature of the $16 \mathrm{~S}$ rRNA gene, and the presence of non-mesophilic-aerobic bacterial, as well as other bacterial cells that fail to grow under the conditions of the experiments (Ramamurthy et al., 2014; Vetrovsky and Baldrian, 2013). However, some inconsistencies of population changes after sanitation were observed between plate count and qPCR analyses for floor CF2, DR1, and DR2 samples from the winter sampling, and DR1 for the summer sampling. These samples were from the surface sites that did not show consistent sanitation effects.

\subsection{Microbiome on environmental surface samples as determined by $16 S$ rRNA gene survey}

The v4 region of 16S rRNA gene was targeted for sequencing analyses, and the sequencing data have been submitted to NCBI (Accession No.: PRJNA428376). After Paired-end merge and quality control analyses using Qiime2, 16S rRNA gene amplicon sequencing of the 80 surface samples from the winter sampling using MiSeq v3 kit generated $13,527,313$ sequence reads in total, with a range of 74,095 to 333,346 reads per sample. Queries to the Greengene database using these sequences identified a total of 6831 OTUs in the 80 surface samples, including 59 archaea, 6355 bacteria, 405 eukaryotes (chloroplast and mitochondria), and 12 unassigned OTUs. All eukaryote reads, which counted for $40.65 \%$ of the total $13,527,313$ reads, and unassigned reads $(0.09 \%)$ were purged prior to data analysis of bacterial communities on surfaces in food environment. The 59 Archaea OTUs were further classified as 16 species, while the bacteria OTUs were classified into 953 species. These bacterial reads represented 35 phyla; 4 of them, Actinobacteria, Bacteroidetes, Firmicutes, and Proteobacteria, had relative abundance of $>1 \%$. An additional 52,343 bacterial reads $(0.39 \%$ of the total reads) can only be assigned to the domain Bacteria.

Sequencing of the 80 surface samples from the summer sampling using MiSeq v2 kit generated 5,503,803 sequence reads in total, with a range of 10,794 to 155,334 reads per sample. A total of 3002 OTUs were identified, including 10 archaea, 2990 bacteria, 61 eukaryotes, and 2 unassigned OTUs. All eukaryote reads ( $31.83 \%$ of the total reads) and unassigned reads $(0.14 \%)$ were purged prior to data analysis. The 2990 bacteria OTUs were classified into 25 phyla and 662 species. Like the winter sampling data, 4 phyla, Actinobacteria, Bacteroidetes, Firmicutes, and Proteobacteria, had relative abundance of $>1 \%$. $0.26 \%$ of the total reads can only be assigned to the domain Bacteria.

Paired-end reads (2079 per sample) of each surface sample were 

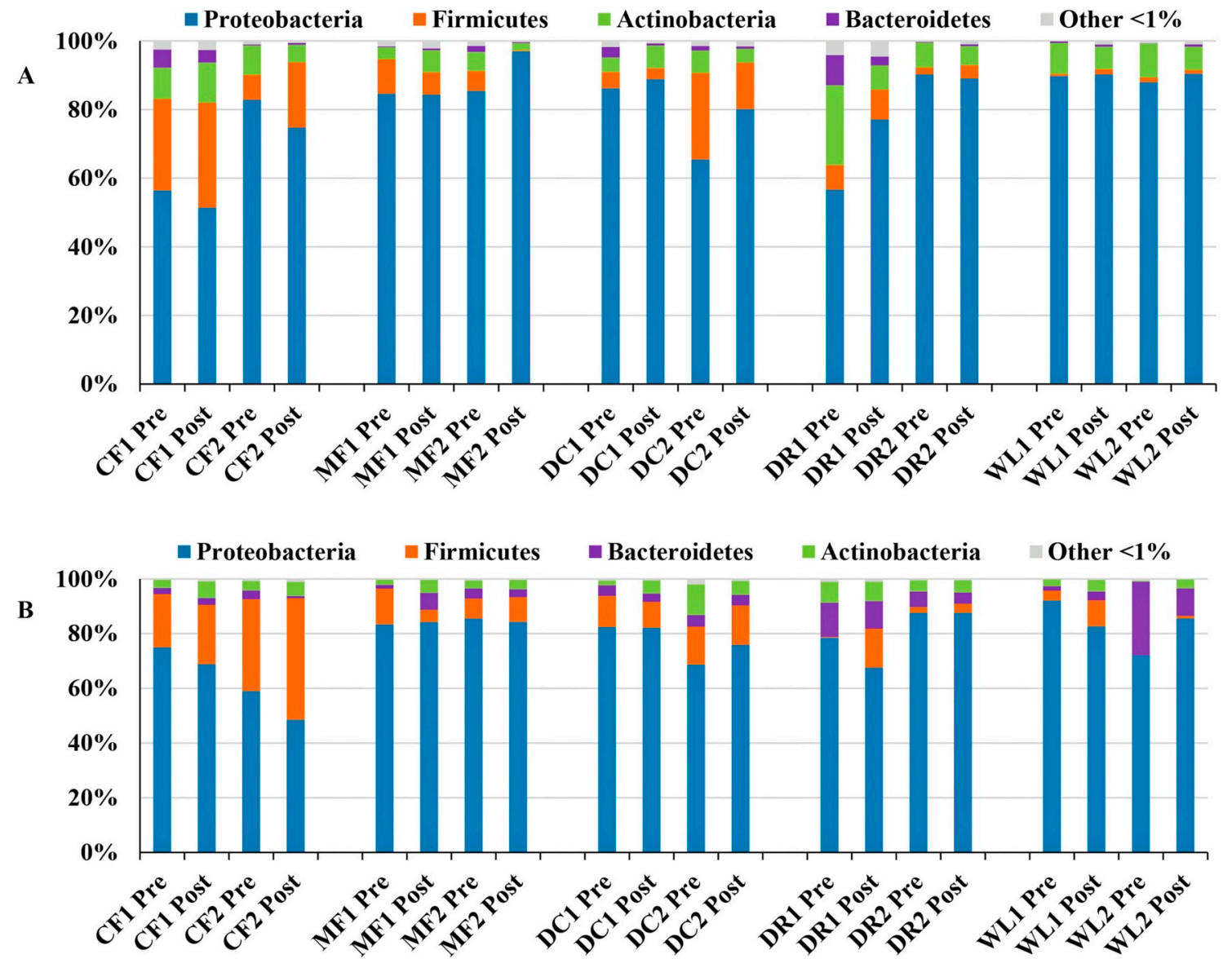

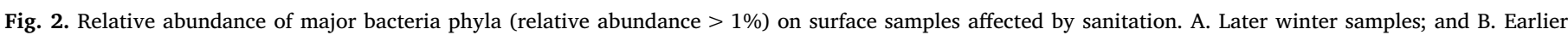
summer samples.

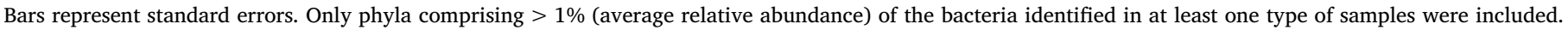

randomly selected for alpha and beta diversity analyses. The evenness of bacterial communities in the 10 sample sites ranged from 0.33 to 0.89 , and the Shannon index ranged from 1.98 to 6.67 (Fig. S1). There were no significant differences among sample sites or between sampling times for the two alpha indexes $(P<0.05)$.

Proteobacteria was the phylum with the highest abundance from the tested surface samples, accounting for $82.8 \%$ and $74.5 \%$ of the total bacterial reads for winter and summer samplings, respectively (Fig. 2). The phyla with the second highest RA in surface samples was Firmicutes $(8.9 \%$ in winter and $11.8 \%$ in summer). Actinobacteria $(7.4 \%$ in winter and $4.4 \%$ in summer) and Bacteroidetes (1.6\% in winter and $5.6 \%$ in summer) were the other two major phyla identified in the processing facility.

At the genus and species level, a Cupriavidus species had the highest average RA in tested surface samples in both winter and summer samplings (Fig. 3). The RA of the identified Ralstonia sp. ranked the 3rd and 7th in winter and summer samplings, respectively. The RA of an unknown species of family Enterobacteriaceae ranked the 2nd and 9th in winter and summer samplings, respectively. Pseudomonas spp. were also the major bacterial taxa identified in the food processing environments (Fig. 3), which has been reported as a common genus on produce and in food production environment (Hibbing et al., 2010; Langsrud et al., 2016; Moretro and Langsrud, 2017). All the most abundant species (top 5) belonged to the phylum Proteobacteria, except a psychrophilic bacterium, Arthrobacter psychrolactophilus (LovelandCurtze et al., 1999), isolated during winter sampling.

\subsection{Zone 3 microbiome impacted by routine sanitation}

At individual species level, the total 16S rRNA gene copy numbers were estimated using information of relative abundance of each species and qPCR determination of total rDNA copy numbers. The effectiveness of sanitation was matched to the changes of species specific 16S rRNA gene copies (Fig. 4) for the top 5 most abundant species. Cupriavidus sp. had the highest population density on average in winter sampling, while 3 Pseudomonas spp. were the top 3 bacteria on sampled surfaces in summer, especially before sanitation.

The 16S rRNA gene copies of Pseudomonas spp. decreased most noticeably on the sample sites that showed significant sanitation effectiveness for both the winter and summer samplings (Figs. 1 and 5). The decreasing rates (slopes) of the Cupriavidus sp. at both sampling times and the Ralstonia sp. in winter sampling on most floor surface sites were significantly lower than that of Pseudomonas spp. Such decrease in 16S rRNA gene copies for the top 5 species were not observed for the sites that did not show significant sanitation effectiveness. Interestingly, regardless the number of copies in the pre-sanitation samples, 16S rRNA gene copy numbers in post-sanitation samples for $\mathrm{Cu}$ priavidus sp., Ralstonia sp., and family $(f$-) Enterobacteriaceae sp. in winter sampling, and Cupriavidus sp. in summer sampling, tended to reach a more comparable level. This observation might suggest that bacterial cells of these species could be redistributed at low levels by the sanitation process itself, or some other mechanism after sanitation.

Fig. 5 shows the divergence of microbiota characteristics at each sample site by principal coordinate analysis (PCoA). In general, the four repeat samples for each sampling event at each site were closely clustered, with few exceptions. In most cases, the clusters were well 
$A$

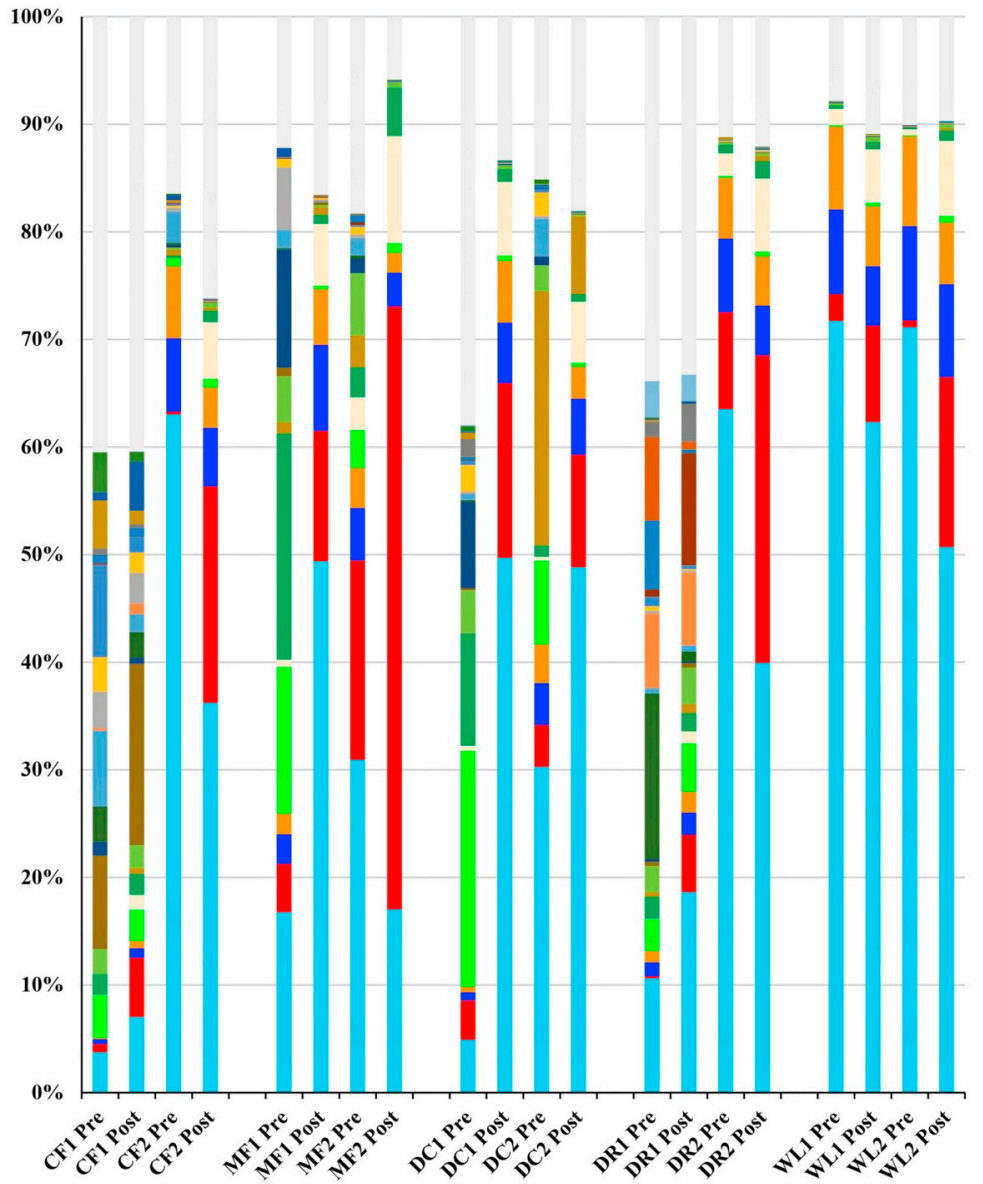

- Cupriavidus sp.

f-Enterobacteriaceae sp.

- Ralstonia sp.

- Arthrobacter psychrolactophilus

- Pseudomonas sp.1

Stenotrophomonas sp.

- Pseudomonas sp.2

- Bacillus cereus

- Pseudomonas veronii

- Planomicrobium sp.

- Pseudomonas viridiflava

- Arthrobacter sp.

- Psychrobacter sp. 1

- Devosia sp.

Exiguobacterium sp.

- Pseudomonas fragi

n Carnobacterium viridans

- Methylobacterium adhaesivum

nChryseobacterium sp.

- f-Brucellaceae sp.

- Polaromonas sp.

- Acinetobacter sp.1

- Buchnera sp.

- Acinetobacter sp.2

f-Rhizobiaceae sp.

Other $<3 \%$
B

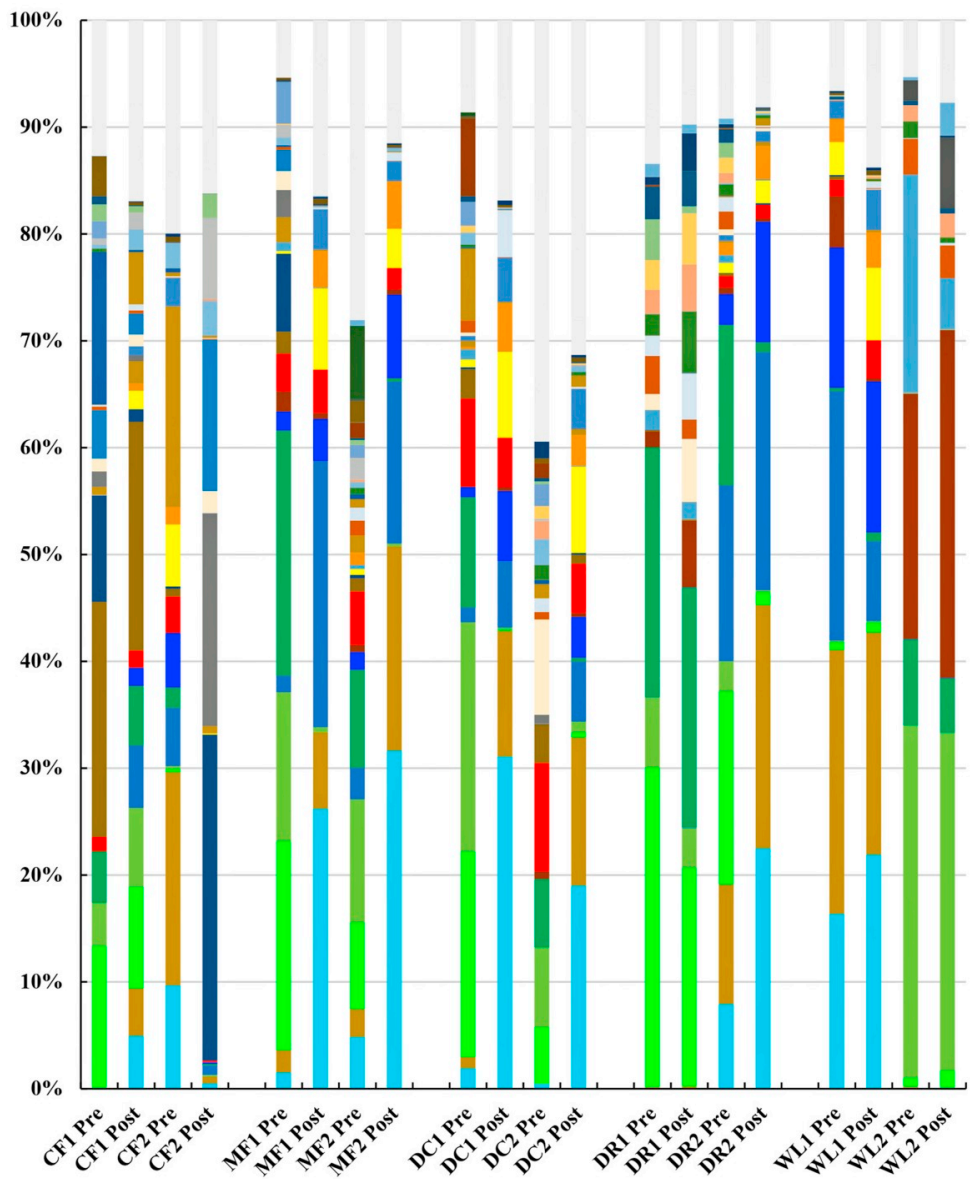

- Cupriavidus sp.

- f-Oxalobacteraceae sp. 1

- Pseudomonas sp.1

- Pseudomonas veronii

- Herbaspirillum sp.

- Pseudomonas sp. 2

- Ralstonia sp.

Methylobacterium adhaesivum

-f-Enterobacteriaceae sp.

- Pseudomonas fragi

- Exiguobacterium sp.

Escherichia coli

- Pedobacter cryoconitis

- Arthrobacter psychrolactophilus

- Bacillus cereus

- Acinetobacter lwoffii

- Streptococcus luteciae

f-Micrococcaceae sp.1

- Planomicrobium sp.

- Chryseobacterium sp.

f-Comamonadaceae $s p$.

- Bacillus sp. 1

-Shewanella sp.

—anthinobacterium lividum

- Bacillus flexus

Pedobacter sp.

- Acinetobacter johnsonii

Polaromonas sp.

Erwinia sp.

- Arthrobacter sp.

- Flavobacterium succinicans

- Yersinia sp.

- f-Bradyrhizobiaceae sp.

-f-Aeromonadaceae sp.

- Sphingomonas sp.

- Serratia marcescen

- Rhodococcus sp.

Other $<3 \%$

Fig. 3. Relative abundance of bacteria species (relative abundance $>3 \%$ ) on surface samples at winter (A) and summer (B) samplings. 

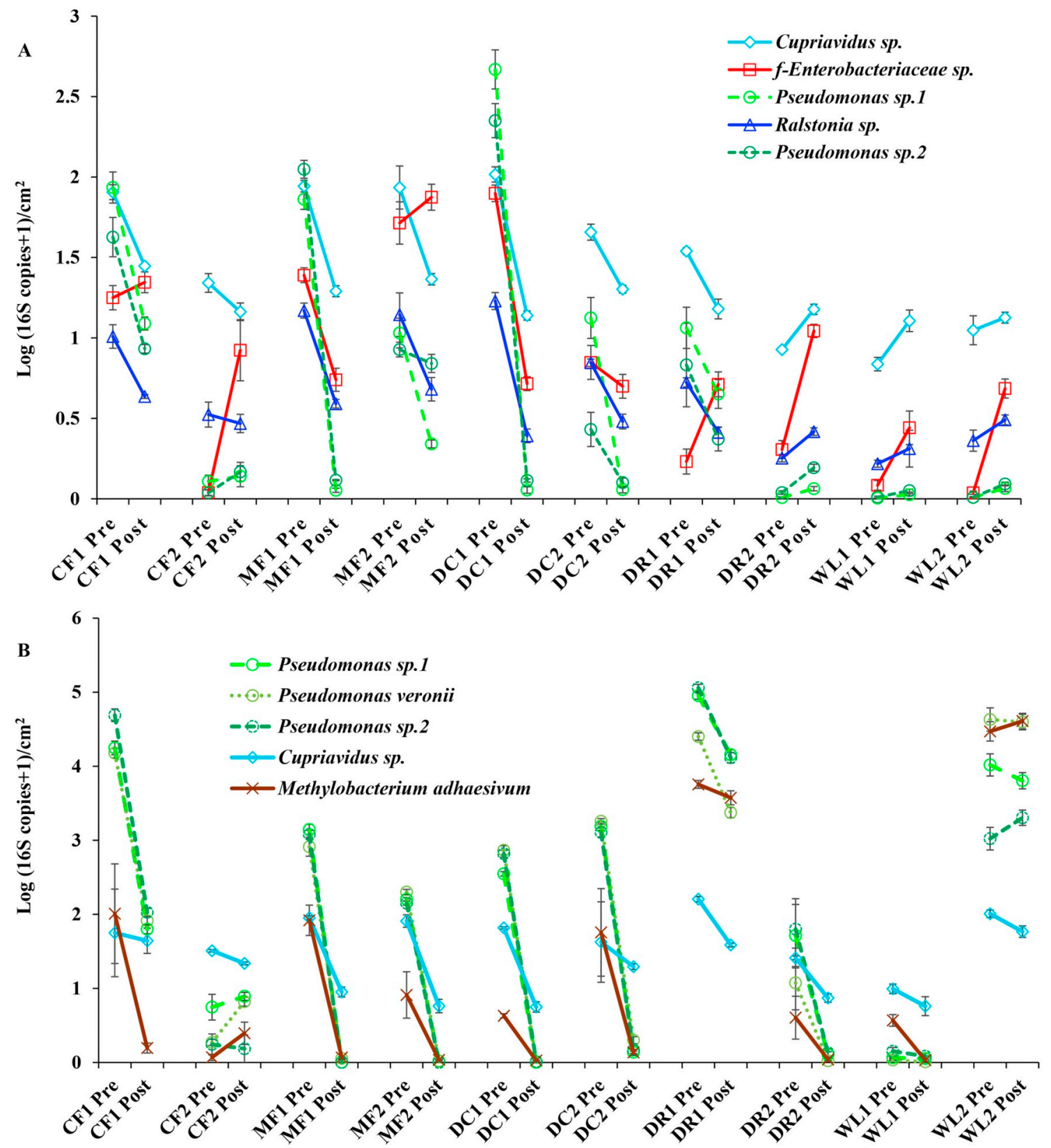

Fig. 4. Population changes of the top 5 bacteria species of surface samples from winter (A) and summer (B) samplings. Bars represent standard errors.

separated by sampling time, indicating considerable dissimilarities at given sampling sites for late winter and early summer. The effect of routine sanitation on microbiota at given samples sites was varied. For those sites that effective sanitation resulted in significant decrease in aerobic bacterial population, greater separation of pre- and post-sanitation clusters was observed (eg. MF1, DC1), indicating that the bacterial population reduction was both quantitative and qualitive. In contrast, less significant cluster separating (eg. DR1, WL1, WL2) was observed for sites that did not show a significant sanitation effect. Overall, greater cluster separation was observed for the summer sampling, possibly a reflection of more effective sanitation, or greater initial microbiome richness.

\subsection{Residential and transient microbiota in processing environment}

The sampling site specific microbiomes derived by 16S rRNA gene amplicon survey provided snapshots of the microbial composition at the sampling time, including both transient and residential microbiota. To generate a more comprehensive view of the residential microbiota in the processing facility, the spatial and temporal presence of the most abundant species were examined at each sampling event. The top 10 species at each sampling site and each sampling event were compiled, which encompassed a total of 70 bacterial species (data not shown). Of these 70 species, 25 appeared only one time as top 10 in any of the samplings, and another 12 appeared as top 10 in $<3$ sample sites at all the events. They seemed typical transient species and were not further discussed. The remaining 33 species are listed in Table 1. Several of these species had greater tendency of appearing in great abundance in either winter (eg. Methylobacterium sp., Agrobacterium sp.) or summer (eg. $f$-Oxalobacteraceae sp., Streptococcus luteciae, Herbaspirillum sp.) sampling and their presence in the processing facility is more likely transient. Such bias was not seen with most of the other species that were frequently found among the most abundant taxa at various sampling sites and events, and were more likely residential to the facility. Several species were more likely to be found in pre-sanitation (eg. Pseudomonas fragi, Pseudomonas viridiflava) or post-sanitation (eg. 


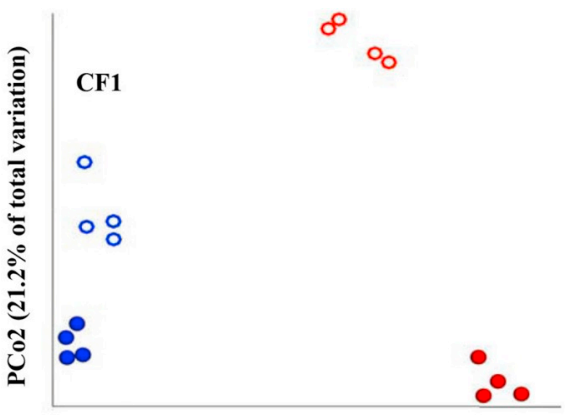

PCo1 (30.8\% of total variation)

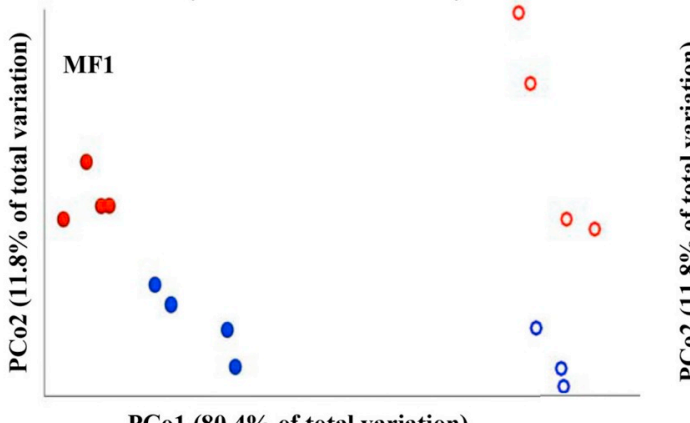

PCo1 (80.4\% of total variation)
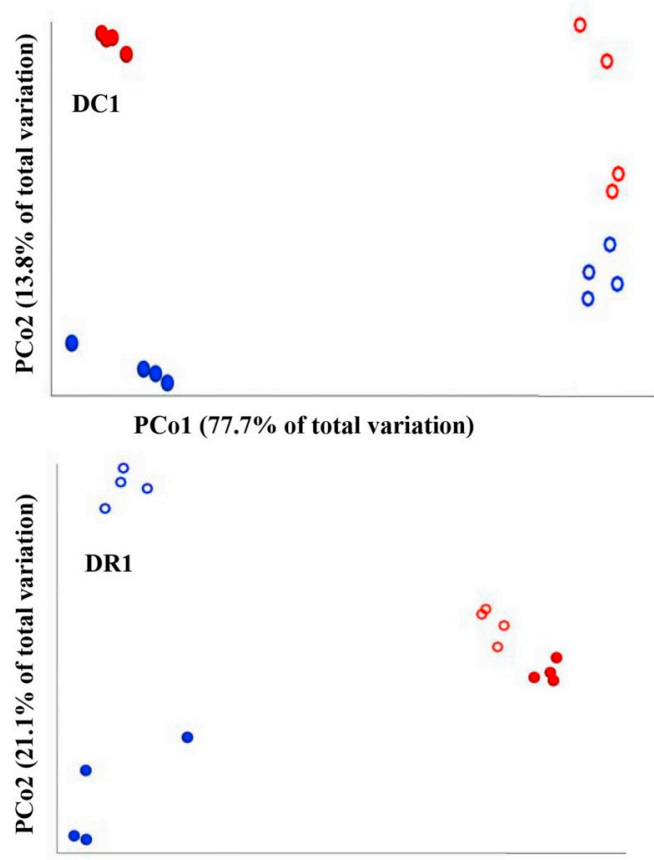

PCo1 (68.6\% of total variation)

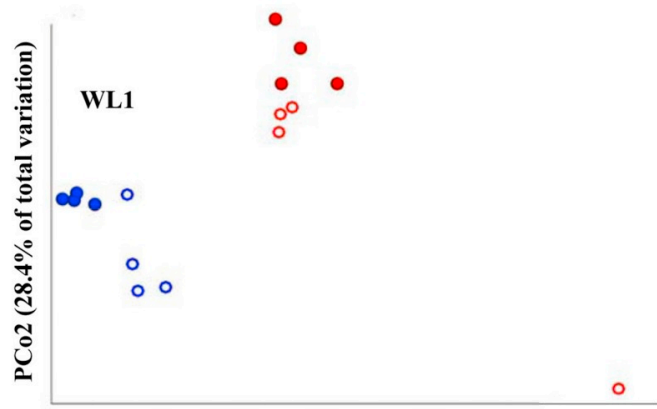

PCo1 (58.1\% of total variation)

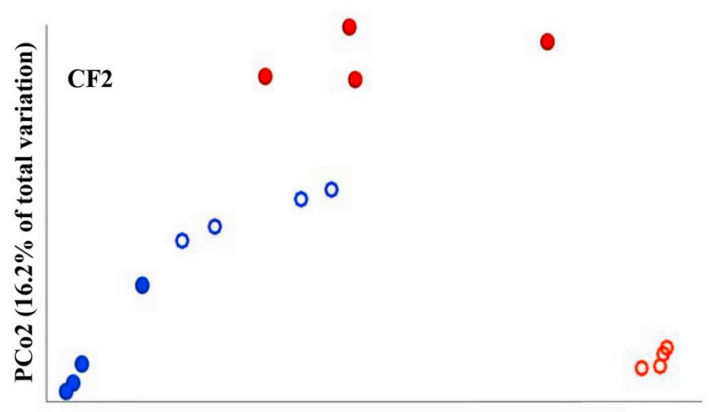

PCo1 (69.9\% of total variation)

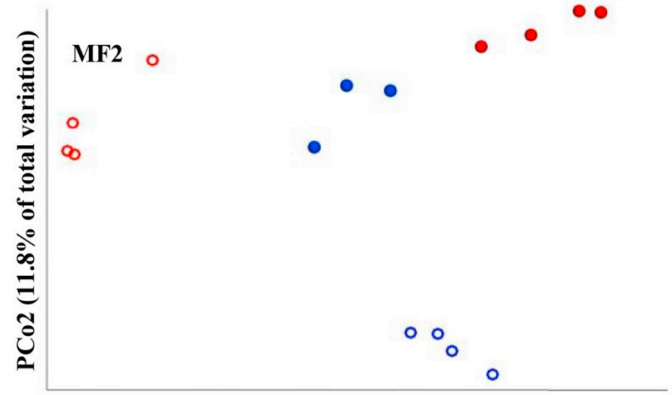

PCo1 (80.4\% of total variation)

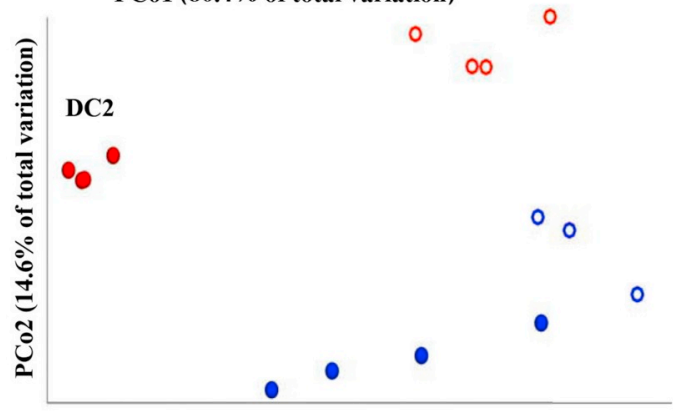

PCo1 (64.3\% of total variation)

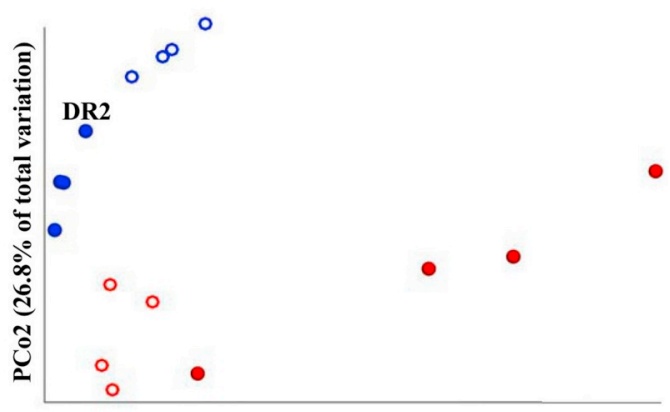

PCo1 (58.0\% of total variation)

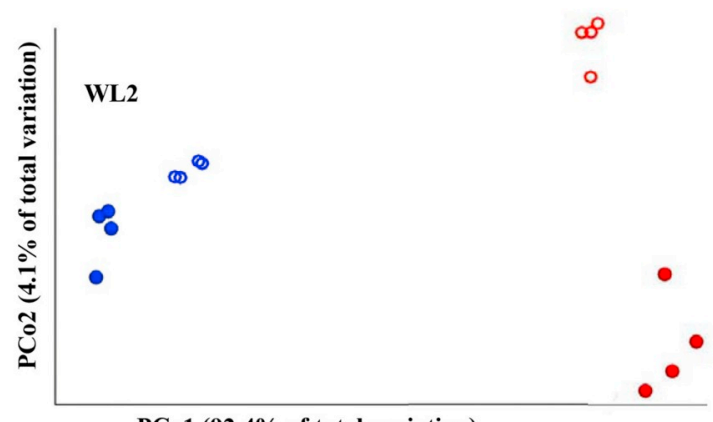

PCo1 (92.4\% of total variation)

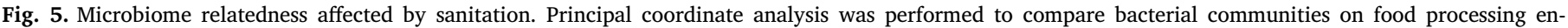

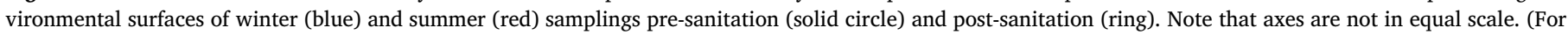
interpretation of the references to color in this figure legend, the reader is referred to the web version of this article.) 
Table 1

Bacterial species frequently present in high abundance in various sampled sites.

\begin{tabular}{|c|c|c|c|c|c|c|c|c|}
\hline \multirow[b]{2}{*}{ Species } & \multicolumn{6}{|c|}{ Frequency $^{\mathrm{a}}$} & \multicolumn{2}{|c|}{ Ratio $^{b}$} \\
\hline & $\begin{array}{c}\text { Site } \\
(n=10)\end{array}$ & $\begin{array}{c}\text { Sample } \\
(n=40)\end{array}$ & $\begin{array}{c}A \\
(n=10)\end{array}$ & $\begin{array}{c}\text { B } \\
(n=10)\end{array}$ & $\begin{array}{c}C \\
(n=10)\end{array}$ & $\begin{array}{c}D \\
(n=10)\end{array}$ & $A C: B D$ & $A B: C D$ \\
\hline Cupriavidus sp. & 10 & 32 & 10 & 10 & 5 & 7 & $15: 17$ & $20: 12$ \\
\hline$f$-Enterobacteriaceae sp. & 10 & 29 & 7 & 10 & 6 & 6 & $13: 16$ & $17: 12$ \\
\hline Pseudomonas sp. & 10 & 28 & 8 & 8 & 8 & 4 & $16: 12$ & $16: 12$ \\
\hline Ralstonia sp. & 9 & 25 & 7 & 8 & 4 & 6 & $11: 14$ & $15: 10$ \\
\hline Arthrobacter psychrolactophilus & 9 & 24 & 7 & 9 & 2 & 6 & 9:15 & $16: 8$ \\
\hline Pseudomonas veronii & 8 & 19 & 5 & 3 & 8 & 3 & $13: 6$ & $8: 11$ \\
\hline Stenotrophomonas sp. & 8 & 13 & 4 & 8 & 1 & 0 & $5: 8$ & $12: 1$ \\
\hline Escherichia coli & 8 & 10 & 1 & 1 & 1 & 7 & $2: 8$ & $2: 8$ \\
\hline f-Comamonadaceae sp. & 7 & 11 & 3 & 5 & 1 & 2 & $4: 7$ & $8: 3$ \\
\hline f-Oxalobacteraceae sp. & 7 & 10 & 1 & 0 & 3 & 6 & $4: 6$ & $1: 9$ \\
\hline Streptococcus luteciae & 7 & 8 & 0 & 0 & 2 & 6 & $2: 6$ & $0: 8$ \\
\hline Herbaspirillum sp. & 7 & 8 & 0 & 0 & 2 & 6 & $2: 6$ & $0: 8$ \\
\hline Bacillus cereus & 6 & 9 & 3 & 3 & 2 & 1 & $5: 4$ & $6: 3$ \\
\hline Morganella morganii & 6 & 6 & 0 & 0 & 1 & 5 & $1: 5$ & $0: 6$ \\
\hline Methylobacterium sp. & 5 & 8 & 5 & 3 & 0 & 0 & $5: 3$ & $8: 0$ \\
\hline Pseudomonas fragi & 4 & 8 & 3 & 0 & 4 & 1 & $7: 1$ & $3: 5$ \\
\hline Arthrobacter sp. & 4 & 6 & 2 & 1 & 2 & 1 & $4: 2$ & $3: 3$ \\
\hline Agrobacterium sp. & 4 & 4 & 1 & 3 & 0 & 0 & $1: 3$ & $4: 0$ \\
\hline$f$-Micrococcaceae sp. & 4 & 4 & 0 & 1 & 1 & 2 & $1: 3$ & $1: 3$ \\
\hline Bacteroides fragilis & 4 & 4 & 0 & 0 & 0 & 4 & $0: 4$ & $0: 4$ \\
\hline Exiguobacterium sp. & 3 & 6 & 2 & 1 & 2 & 1 & $4: 2$ & $3: 3$ \\
\hline Planomicrobium sp. & 3 & 5 & 1 & 1 & 2 & 1 & $3: 2$ & $2: 3$ \\
\hline Pedobacter sp. & 3 & 5 & 0 & 1 & 2 & 2 & $2: 3$ & $1: 4$ \\
\hline Chryseobacterium sp. & 3 & 5 & 1 & 0 & 3 & 1 & $4: 1$ & $1: 4$ \\
\hline Methylobacterium adhaesivum & 3 & 5 & 0 & 1 & 2 & 2 & $2: 3$ & $1: 4$ \\
\hline Psychrobacter sp. & 3 & 4 & 2 & 0 & 1 & 1 & $3: 1$ & $2: 2$ \\
\hline Acinetobacter sp. & 3 & 4 & 2 & 0 & 1 & 1 & $3: 1$ & $2: 2$ \\
\hline Janthinobacterium lividum & 3 & 4 & 1 & 1 & 1 & 1 & $2: 2$ & $2: 2$ \\
\hline Cryocola sp. & 3 & 4 & 3 & 1 & 0 & 0 & $3: 1$ & $4: 0$ \\
\hline Pseudomonas viridiflava & 3 & 3 & 2 & 0 & 1 & 0 & $3: 0$ & $2: 1$ \\
\hline Bacillus sp. & 3 & 3 & 0 & 1 & 1 & 1 & $1: 2$ & $1: 2$ \\
\hline Erwinia sp. & 3 & 3 & 0 & 0 & 3 & 0 & $3: 0$ & $0: 3$ \\
\hline Corynebacterium sp. & 3 & 3 & 3 & 0 & 0 & 0 & $3: 0$ & $3: 0$ \\
\hline
\end{tabular}




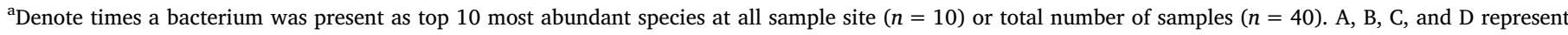
winter sampling pre-sanitation, winter sampling post-sanitation, summer sampling pre-sanitation, and summer sampling post-sanitation samples.

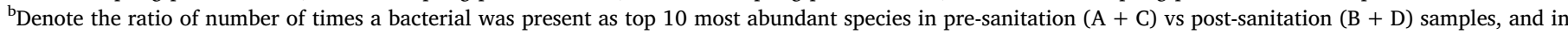
winter $(A+B)$ and Summer $(C+D)$ samples. Green and yellow highlights examples of species with apparent biased distributions.

Morganella morganii, Bacteroides fragilis) samples, which might hint for decreased or increased sensitivity, respectively, to routine sanitation. Several other species, including Cupriavidus sp., $f$-Enterobacteriaceae sp., Pseudomonas sp., Ralstonia sp., Arthrobacter psychrolactophilus, Pseudomonas veronii, and Stenotrophomonas sp., consistently appeared in high abundance at nearly all the sampling sites at multiple sampling events, and are likely to constitute the core residential microbiota of the processing facility. This view is consistent with previous observation that packaged spinach from the same facility had significantly increased copies of Cupriavidus sp., $f$-Enterobacteriaceae sp., and Ralstonia sp. rDNA compared to that on spinach before washing (Gu et al., 2018), which may suggest the presence of these bacteria as biofilms in water system or other food contact materials or surfaces (Fairbrother et al., 2013; Lerch et al., 2017; Liu et al., 2016). Due to the low ambient temperature at the processing environment, microorganisms thriving at or tolerant to low temperatures were expected to be among the residential microbiota. Indeed, multiple psychrophilic bacteria, including Arthrobacter psychrolactophilus and Psychrobacter sp. (Loveland-Curtze et al., 1999; Bozal et al., 2003), were identified among the top 10 dominant species. Species of several dominant genera identified in this study, like Pseudomonas, were also reported to be psychrophilic (Singh et al., 2009). Nevertheless, bacterial species and genera generally characterized as mesophilic were abundantly represented among the proposed core residential microbiota, as determined by the culture-independent metagenomic analyses, which underlines the complexity of residential microbiota establishment. Identification of the core residential microbiota in processing facilities could facilitate the sanitization strategies and development of preventive controls to improve food safety during commercial processing operations.

\section{Conclusion}

Zone 3 microbiome in a fresh produce processing facility was examined by 16S rRNA gene amplicon survey, using surface samples taken from diverse locations and surface types before and after routine sanitation during winter and summer seasons. Viable bacterial counts on various types of surfaces on the production floors were more consistently and significantly reduced after sanitation compared to the peripheral surfaces. Effective sanitation was correlated to greater reduction in bacteria populations and shifts of the surface microbiome. Based on their nearly ubiquitous abundant presence among various surfaces samples, Cupriavidus sp., $f$-Enterobacteriaceae sp., Pseudomonas sp., Ralstonia sp., and a small number of other species were proposed components of core residential microbiome in the fresh produce processing facility. This provides contextual information on the microbial ecology of diverse bacterial communities on different types of surfaces in fresh-cut produce processing environments, which can benefit further studies on the interaction of microbes during produce production, and the prevention of cross contamination of foodborne pathogens and spoilage microorganisms, leading to better understanding of the dynamics and population heterogeneity of microbial communities in a complex food system.

Supplementary data to this article can be found online at https:// doi.org/10.1016/j.ijfoodmicro.2019.02.002.

\section{Acknowledgments}

Authors thank the unnamed commercial fresh-cut processor for access to the facility for sampling. This project is partially supported by a research grant from USDA-NIFA Specialty Crop Research Initiative, Award No. 2016-51181-25403. LW was a visiting graduate student at
ARS and was funded by Chinese Scholarship Council for Oversea Studies.

Mention of trade names or commercial products in this publication is solely for the purpose of providing specific information and does not imply recommendation or endorsement by the U.S. Department of Agriculture.

The U.S. Department of Agriculture (USDA) prohibits discrimination in all its programs and activities on the basis of race, color, national origin, age, disability, and where applicable, sex, marital status, familial status, parental status, religion, sexual orientation, genetic information, political beliefs, reprisal, or because all or part of an individual's income is derived from any public assistance program. (Not all prohibited bases apply to all programs.) Persons with disabilities who require alternative means for communication of program information (Braille, large print, audiotape, etc.) should contact USDA's TARGET Center at (202) 7202600 (voice and TDD). To file a complaint of discrimination, write to USDA, Director, Office of Civil Rights, 1400 Independence Avenue, S.W., Washington, D.C. 20250-9410, or call (800) 795-3272 (voice) or (202) 720-6382 (TDD). USDA is an equal opportunity provider and employer.

\section{References}

Aguado, V., Vitas, A.I., Garcia-Jalon, I., 2004. Characterization of Listeria monocytogenes and Listeria innocua from a vegetable processing plant by RAPD and REA. Int. J. Food Microbiol. 90, 341-347.

Apprill, A., McNally, S., Parsons, R., Weber, L., 2015. Minor revision to V4 region SSU rRNA 806R gene primer greatly increases detection of SAR11 bacterioplankton. Aquat. Microb. Ecol. 75, 129-137.

Bokulich, N.A., Lewis, Z.T., Boundy-Mills, K., Mills, D.A., 2016. A new perspective on microbial landscapes within food production. Curr. Opin. Biotechnol. 37, 182-189.

Bozal, N., Montes, M.J., Tudela, E., Guinea, J., 2003. Characterization of several Psychrobacter strains isolated from Antarctic environments and description of Psychrobacter luti sp. nov. and Psychrobacter fozii sp. nov. Int. J. Syst. Evol. Microbiol. 53, 1093-1100.

Brankatschk, R., Bodenhausen, N., Zeyer, J., Bürgmann, H., 2012. Simple absolute quantification method correcting for quantitative PCR efficiency variations for microbial community samples. Appl. Environ. Microbiol. 78, 4481-4489.

Brouillette, R., 2018. The importance of hygienic zoning to prevent product contamination. Available at. https://www.foodsafetymagazine.com/magazine-archive1/ junejuly-2018/the-importance-of-hygienic-zoning-to-prevent-productcontamination, Accessed date: 23 January 2019 (Food Safety Magazine).

Callahan, B.J., McMurdie, P.J., Rosen, M.J., Han, A.W., Johnson, A.J., Holmes, S.P., 2016 DADA2: high-resolution sample inference from Illumina amplicon data. Nat. Methods $13,581-583$.

Caporaso, J.G., Lauber, C.L., Walters, W.A., Berg-Lyons, D., Lozupone, C.A., Turnbaugh, P.J., Fierer, N., Knight, R., 2011. Global patterns of 16S rRNA diversity at a depth of millions of sequences per sample. Proc. Natl. Acad. Sci. U. S. A. 108, 4516-4522.

Caporaso, J.G., Lauber, C.L., Walters, W.A., Berg-Lyons, D., Huntley, J., Fierer, N., Owens, S.M., Betley, J., Fraser, L., Bauer, M., Gormley, N., Gilbert, J.A., Smith, G., Knight, R., 2012. Ultra-high-throughput microbial community analysis on the Illumina HiSeq and MiSeq platforms. ISME J. 6, 1621-1624.

CDC, 2018. List of selected multistate foodborne outbreak investigations. Available at: https://www.cdc.gov/foodsafety/outbreaks/multistate-outbreaks/outbreaks-list. html, Accessed date: 23 January 2019.

Chiao, T.H., Clancy, T.M., Pinto, A., Xi, C.W., Raskin, L., 2014. Differential resistance of drinking water bacterial populations to monochloramine disinfection. Environ. Sci. Technol. 48, 4038-4047.

Clifford, R.J., Milillo, M., Prestwood, J., Quintero, R., Zurawski, D.V., Kwak, Y.I. Waterman, P.E., Lesho, E.P., Mc Gann, P., 2012. Detection of bacterial 16S rRNA and identification of four clinically important bacteria by real-time PCR. PLoS One 7, e48558.

Fairbrother, L., Etschmann, B., Brugger, J., Shapter, J., Southam, G., Reith, F., 2013 Biomineralization of gold in biofilms of Cupriavidus metallidurans. Environ. Sci. Technol. 47, 2628-2635.

FDA, 2018. Swabbing zones, understanding zones and interpretation of data. Available at: http://www.afdo.org/Resources/Documents/4-news-and-events/pastpresentations/1006190900Zink.pdf, Accessed date: 23 January 2019.

Ferreira, V., Wiedmann, M., Teixeira, P., Stasiewicz, M., 2014. Listeria monocytogenes persistence in food-associated environments: epidemiology, strain characteristics, and implications for public health. J. Food Prot. 77, 150-170.

Gu, G.Y., Ottesen, A., Bolten, S., Ramachandran, P., Reed, E., Rideout, S., Luo, Y.G., Patel, 
J., Brown, E., Nou, X.W., 2018. Shifts in spinach microbial communities after chlorine washing and storage at compliant and abusive temperatures. Food Microbiol. 73, 73-84.

Hibbing, M.E., Fuqua, C., Parsek, M.R., Peterson, S.B., 2010. Bacterial competition: surviving and thriving in the microbial jungle. Nat. Rev. Microbiol. 8, 15-25.

Holah, J.T., Bird, J., Hall, K.E., 2004. The microbial ecology of high-risk, chilled food factories; evidence for persistent Listeria spp. and Escherichia coli strains. J. Appl. Microbiol. 97, 68-77.

Hultman, J., Rahkila, R., Ali, J., Rousu, J., Bjorkroth, K.J., 2015. Meat processing plant microbiome and contamination patterns of cold-tolerant bacteria causing food safety and spoilage risks in the manufacture of vacuum-packaged cooked sausages. Appl. Environ. Microbiol. 81, 7088-7097.

Kaneko, K.I., Hayashidani, H., Takahashi, K., Shiraki, Y., Limawongpranee, S., Ogawa, M., 1999. Bacterial contamination in the environment of food factories processing readyto-eat fresh vegetables. J. Food Prot. 62, 800-804.

Katoh, K., Standley, D.M., 2013. MAFFT multiple sequence alignment software version 7: improvements in performance and usability. Mol. Biol. Evol. 30, 772-780.

Kloepper, J.W., Beauchamp, C.J., 1992. A review of issues related to measuring colonization of plant roots by bacteria. Can. J. Microbiol. 38, 1219-1232.

Langsrud, S., Moen, B., Moretro, T., Loype, M., Heir, E., 2016. Microbial dynamics in mixed culture biofilms of bacteria surviving sanitation of conveyor belts in salmonprocessing plants. J. Appl. Microbiol. 120, 366-378.

Lerch, T.Z., Chenu, C., Dignac, M.F., Barriuso, E., Mariotti, A., 2017. Biofilm vs. planktonic lifestyle: consequences for pesticide 2,4-D metabolism by Cupriavidus necator JMP134. Front. Microbiol. 8, 904.

Liang, X., Bushman, F.D., FitzGerald, G.A., 2015. Rhythmicity of the intestinal microbiota is regulated by gender and the host circadian clock. Proc. Natl. Acad. Sci. U. S. A. 112, 10479-10484.

Liu, N.T., Bauchan, G.R., Francoeur, C.B., Shelton, D.R., Lo, Y.M., Nou, X., 2016. Ralstonia insidiosa serves as bridges in biofilm formation by foodborne pathogens Listeria monocytogenes, Salmonella enterica, and enterohemorrhagic Escherichia coli. Food Control 65, 14-20.

Loveland-Curtze, J., Sheridan, P.P., Gutshall, K.R., Brenchley, J.E., 1999. Biochemical and phylogenetic analyses of psychrophilic isolates belonging to the Arthrobacter subgroup and description of Arthrobacter psychrolactophilus, sp. nov. Arch. Microbiol. $171,355-363$.

Luo, Z., Gu, G., Ginn, A., van Bruggen, A.H.C., Danyluk, M., Wright, A., 2016. Distribution and characterization of Salmonella enterica isolates from irrigation ponds in southeastern U.S.A. Appl. Environ. Microbiol. 81, 4376-4387.

Mandal, S., Van Treuren, W., White, R.A., Eggesbo, M., Knight, R., Peddada, S.D., 2015. Analysis of composition of microbiomes: a novel method for studying microbial composition. Microb. Ecol. Health Dis. 26, e27663.

McDonald, D., Clemente, J.C., Kuczynski, J., Rideout, J.R., Stombaugh, J., Wendel, D., Wilke, A., Huse, S., Hufnagle, J., Meyer, F., Knight, R., Caporaso, J.G., 2012. The biological observation matrix (BIOM) format or: how I learned to stop worrying and love the ome-ome. Gigascience 1, e7.

Moretro, T., Langsrud, S., 2017. Residential bacteria on surfaces in the food industry and their implications for food safety and quality. Compr. Rev. Food Sci. Food Saf. 16, 1022-1041.

Moretro, T., Moen, B., Heir, E., Hansen, A.A., Langsrud, S., 2016. Contamination of salmon fillets and processing plants with spoilage bacteria. Int. J. Food Microbiol. 237, 98-108.

Nocker, A., Richter-Heitmann, T., Montijn, R., Schuren, F., Kort, R., 2010. Discrimination between live and dead cells in bacterial communities from environmental water samples analyzed by 454 pyrosequencing. Int. Microbiol. 13, 59-65.

Pappelbaum, K., Grif, K., Heller, I., Wurzner, R., Hein, I., Ellerbroek, L., Wagner, M., 2008. Monitoring hygiene on- and at-line is critical for controlling Listeria monocytogenes during produce processing. J. Food Prot. 71, 735-741.

Parada, A.E., Needham, D.M., Fuhrman, J.A., 2016. Every base matters: assessing small subunit rRNA primers for marine microbiomes with mock communities, time series and global field samples. Environ. Microbiol. 18, 1403-1414.

Pérez-Rodríguez, F., Skandamis, P., Valdramidis, V., 2018. Quantitative Methods for Food Safety and Quality in the Vegetable Industry. SpringerLink.

Price, M.N., Dehal, P.S., Arkin, A.P., 2010. FastTree 2-approximately maximum-likelihood trees for large alignments. PLoS One 5, e9490.

Ramamurthy, T., Ghosh, A., Pazhani, G.P., Shinoda, S., 2014. Current perspectives on viable but non-culturable (VBNC) pathogenic bacteria. Front. Public Health 2, e2014.

Simmons, C.K., Wiedmann, M., 2018. Identification and classification of sampling sites for pathogen environmental monitoring programs for Listeria monocytogenes: results from an expert elicitation. Food Microbiol. 75, 2-17.

Singh, A.K., Pindi, P.K., Dube, S., Sundareswaran, V.R., Shivaji, S., 2009. Importance of trmE for growth of the psychrophile Pseudomonas syringae at low temperatures. Appl. Environ. Microbiol. 75, 4419-4426.

Stellato, G., Utter, D.R., Voorhis, A., De Angelis, M., Eren, A.M., Ercolini, D., 2017. A few Pseudomonas oligotypes dominate in the meat and dairy processing environment. Front. Microbiol. 8.

Vazquez-Baeza, Y., Pirrung, M., Gonzalez, A., Knight, R., 2013. EMPeror: a tool for visualizing high-throughput microbial community data. Gigascience 2, 16.

Vetrovsky, T., Baldrian, P., 2013. The variability of the 16S rRNA gene in bacterial genomes and its consequences for bacterial community analyses. PLoS One 8 , e57923. 